\title{
Use of whole mussels and mussel gills in metal pollution biomonitoring
}

\section{Uso del mejillón entero y de sus branquias en el biomonitoreo de la contaminación por metales}

\author{
Paula Sánchez-Marín ${ }^{1,2 *}$, Victoria Besada ${ }^{2}$, Ricardo Beiras ${ }^{1}$ \\ 1 Toralla Marine Science Station (ECIMAT), University of Vigo, Illa de Toralla, E-36331, Vigo, Galicia, Spain. \\ 2 Instituto Español de Oceanografía, IEO, Centro Oceanográfico de Vigo, Subida a Radio Faro, 50, E-36390 \\ Vigo, Spain. \\ * Corresponding author. E-mail: paula.sanchez@ieo.es
}

\begin{abstract}
The use of marine bivalves in metal pollution monitoring is undoubtedly one of the best tools to evaluate metal pollution in coastal areas worldwide. However, since bivalves integrate metal pollution from both the dissolved and the particulate phases, it cannot be assured that metal bioaccumulation in their tissues will predict the risk posed by metals to sensitive organisms such as invertebrate larvae or microalgae, which are known to be mainly affected by the free metal ion fraction. This study aims to test the usefulness of mussel gills-the primary exchange surfaces with dissolved metals-in reflecting dissolved metal bioavailability in the field. For that, we analyzed metal concentrations in environmental samples (whole soft tissues of mussels, mussel gills, sediment, and particulate and dissolved fractions in the water column) collected from 7 sampling sites during a multi-year investigative monitoring survey in the Ría de Vigo. The results showed a different pattern of $\mathrm{Cu}$ and $\mathrm{Zn}$ accumulation in gills compared to whole soft tissues, and these differences are attributable to the faster response of gills to changes in dissolved metal concentrations and to the regulation of essential metals at the whole body level. In the case of $\mathrm{Pb}$, by contrast, concentrations in gills were very similar to those in the whole body. The use of mussel gills in metal pollution biomonitoring is a promising tool for the detection of changes in bioavailable metals in the environment, especially for essential metals such as $\mathrm{Cu}$ and $\mathrm{Zn}$.
\end{abstract}

Keywords: bioaccumulation, metal bioavailability, mussels, Ría de Vigo.

RESUMEN. El uso de bivalvos marinos en el biomonitoreo de la contaminación por metales es sin duda una de las mejores herramientas disponibles para evaluar la contaminación por metales en áreas costeras de todo el mundo. Sin embargo, debido a que los bivalvos integran la contaminación por metales presentes en las fases disuelta y particulada, no está claro que la bioacumulación de metales en sus tejidos sirva para predecir el riesgo causado por los metales sobre los organismos más sensibles, como lo son las larvas de invertebrados o las microalgas, que se ven afectados principalmente por la fracción libre del metal en forma iónica. El presente estudio pretende evaluar la utilidad de las branquias de mejillón-la principal superficie de intercambio con el metal disuelto-para reflejar la biodisponibilidad del metal disuelto en el campo. Para ello, hemos analizado las concentraciones de metales en muestras ambientales (tejidos blandos enteros y branquias de mejillón, sedimento, fracción disuelta y particulada en la columna de agua) recogidas en 7 puntos de muestreo durante una campaña investigativa de seguimiento de la contaminación en la ría de Vigo. Los resultados mostraron un patrón diferente en la acumulación de Cu y Zn en branquias en comparación con los tejidos blandos enteros, siendo estas diferencias atribuibles a la más rápida respuesta de las branquias a cambios en las concentraciones de metales disueltos, así como a la regulación de metales esenciales a nivel de organismo entero. En el caso del Pb, por el contrario, las concentraciones en branquias fueron muy similares a las observadas en el cuerpo entero. El uso de branquias de mejillón en el biomonitoreo de la contaminación por metales es una herramienta prometedora para la detección de cambios en la cantidad de metales biodisponibles en el medio ambiente, en especial para metales esenciales como el $\mathrm{Cu}$ y el $\mathrm{Zn}$.

Palabras clave: bioacumulación, biodisponibilidad de metales, mejillones, ría de Vigo.

\section{INTRODUCTION}

Bivalve mollusks, specially mussels, are frequently used in environmental pollution monitoring (Kimbrough et al. 2008). As sessile and filter feeding organisms, they bioaccumulate compounds present in the environment and provide a time-integrated measure of pollution at a given site (Sericano 2000). For a bivalve mollusk to be used as a biological monitor "a correlation [must exist] between the pollutant content of the organism and the average pollutant concentration in the surrounding habitat" (Sericano

\section{INTRODUCCIÓN}

Los moluscos bivalvos, especialmente los mejillones, frecuentemente son usados en el monitoreo de la contaminación ambiental (Kimbrough et al. 2008). Como organismos sésiles y filtradores, acumulan compuestos presentes en el medioambiente y proveen una medida integrada en el tiempo de la contaminación en un sitio determinado (Sericano 2000). Para que los moluscos bivalvos puedan ser usados como monitores biológicos "[debe existir] una correlación entre el contenido del contaminante en el organismo y la concentración 
2000). In the case of organic contaminants, direct relationships are usually observed between bioaccumulation in mussels and environmental concentrations in both water and sediments (Baumard et al. 1999, Beiras et al. 2003b, Solaun et al. 2015). Such relationships have also been reported for metals in some cases (Yap et al. 2002, Beiras et al. 2003a), but no relationship has been observed in others (Gundacker 1999, Beiras et al. 2003a, Giarratano et al. 2010).

Several factors are implied in the final metal concentrations observed in mussels, including physicochemical (uptake route, chemical speciation of metals in both the dissolved and particulate phases) and biological (filtration rate, ability to regulate internal concentrations, physiological state) ones. These factors contribute to the complexity of the prediction of metal bioaccumulation at a given site and can account for the lack of correlation between metals in organisms and metals in environmental compartments. To account for all or most of these factors and processes, mechanistic biodynamic models have been developed. These models integrate the uptake of dissolved metals via the gills, the assimilation of metals from ingested particles, and the excretion of metals into a single equation that predicts the concentrations of metals in the organism at the steady state (Griscom et al. 2002, Luoma and Rainbow 2005). Biodynamic models have proven successful in the forecast of metal bioaccumulation in bivalve mollusks, but what happens with forecasting in the opposite direction? Are bivalve mollusks useful indicators of the risk metals pose to the ecosystem?

According to the free ion activity model (Campbell 1995) and the biotic ligand model (Di Toro et al. 2001), the free ion is the most reactive fraction of a metal, and this is the fraction that should be controlled given the risk its toxicity poses on the most sensitive organisms, such as invertebrate larvae. It would therefore be very useful to find a biomonitor, sessile and widespread like mussels, that can reflect only the bioavailability of dissolved metals, since metal concentrations in mussels are the result of the integration of both dissolved and particulate metal uptake routes. We hypothesize that mussel gills can be used for this purpose. Given that gills are the main exchange surface for dissolved metals, they are expected to reflect the bioavailability of dissolved metals and to respond rapidly to changes in dissolved metal bioavailability, in comparison to the whole organism, which is more influenced by the digestive pathway, the stage in the gametogenic cycle, metal detoxification mechanisms, and other physiological processes. The present study analyzed metal concentrations in gills and whole soft tissues of Mytilus galloprovincialis mussels sampled from sites showing different degrees of metal pollution, to find relationships with concentrations in the environment, including sediment, water, and particulate matter, and determine the performance of these tissues as metal biomonitors. promedio del contaminante en el medioambiente que los rodea" (Sericano 2000). En el caso de los contaminantes orgánicos, generalmente, se observan relaciones directas entre la bioacumulación en mejillones y las concentraciones ambientales tanto en la columna de agua como en los sedimentos (Baumard et al. 1999, Beiras et al. 2003b, Solaun et al. 2015). Estas relaciones también han sido reportadas para los metales en algunos casos (Yap et al. 2002, Beiras et al. 2003a), pero en otros no se ha observado una relación (Gundacker 1999, Beiras et al. 2003a, Giarratano et al. 2010).

Son varios los factores que afectan a las concentraciones de metales finales reflejadas en los mejillones, incluidos los factores fisicoquímicos (ruta de captación, especiación química de metales tanto en la fase disuelta como en la particulada) y biológicos (tasa de filtración, capacidad de regular las concentraciones internas, estado fisiológico). Estos factores contribuyen a la complejidad de la predicción de la bioacumulación en un sitio determinado y pueden explicar la falta de correlación entre los metales en los organismos y los metales en los compartimentos ambientales. Para contemplar todos o la mayoría de estos factores y procesos, se han desarrollado modelos mecanicistas biodinámicos. Estos modelos integran la captación de metales disueltos a través de las branquias, la asimilación de metales de partículas ingeridas y la excreción de metales en una única ecuación que predice las concentraciones de metales en el organismo en estado estacionario (Griscom et al. 2002, Luoma y Rainbow 2005). Los modelos biodinámicos han sido exitosos en el pronóstico de la bioacumulación de metales en moluscos bivalvos, pero ¿qué ocurre con el pronóstico en el sentido contrario? ¿Son los moluscos bivalvos útiles indicadores del riesgo que presentan los metales para el ecosistema?

De acuerdo con el modelo de actividad del ion libre (Campbell 1995) y el modelo del ligando biótico (Di Toro et al. 2001), el ion libre es la fracción más reactiva de un metal, y esta es la fracción que debe ser controlada debido al riesgo que representa su toxicidad para los organismos más sensibles, como las larvas de invertebrados. Por lo tanto, sería muy útil encontrar un biomonitor, sésil y ampliamente distribuido como el mejillón, que refleje la biodisponibilidad de únicamente el metal disuelto, dado que los mejillones integran rutas de captación tanto de metales disueltos como de metales particulados. Hipotetizamos que las branquias de mejillón pueden ser usadas para este propósito. Como las branquias son la principal superficie de intercambio para los metales disueltos, se esperaría que reflejen la disponibilidad de metales disueltos y respondan rápidamente a los cambios de la biodisponibilidad de metales disueltos, en comparación con el organismo entero, que está más influenciado por la vía digestiva, el estadio del ciclo gametogénico, los mecanismos de detoxificación de metales y otros procesos fisiológicos. El presente estudio analiza las concentraciones de metales en las branquias y los tejidos blandos enteros de mejillones (Mytilus galloprovincialis) muestreados en sitios que presentan distintos grados de contaminación, con el 


\section{MATERIALS AND METHOdS}

\section{Sampling}

Sampling was performed during an investigative monitoring of marine pollution in Ría de Vigo (Galicia, NW Spain), which included 4 sampling campaigns, in March and October 2004, March 2005, and April 2006 (Beiras et al. 2012). Sampling was performed at 7 sites (Fig. 1). Five of these sites ranged from clean to moderately polluted and were located from the outermost (BA) to the innermost (RE) part of the ria, 3 of which were under the influence of the Cangas (CA), Moaña (MO), and Vigo (AG) urban areas. The other 2 sites (ViB and ViN) were located in the industrial Vigo Harbor and can be considered heavily impacted sites. AG, MO, and RE were revisited during the 4 sampling campaigns, $\mathrm{CA}$ and $\mathrm{ViB}$ were sampled during the last 3 campaigns, and $\mathrm{BA}$ and $\mathrm{ViN}$ were visited only once, so that the data set comprised 20 data points.

Sampling of mussels, water, and sediment was performed on the same day for each sampling campaign. Mussels (M. galloprovincialis) between 40 and $55 \mathrm{~mm}$ in size were collected from the lower intertidal area by hand. Water and sediment samples were collected from the R/V Navaz (Spanish Oceanographic Institution) using Go-Flo bottles and a box corer, respectively. Water was objetivo de encontrar relaciones con las concentraciones en el ambiente, como el sedimento, agua y materia particulada, y determinar el desempeño de estos tejidos como biomonitores de metales.

\section{Materiales Y MÉTOdos}

\section{Muestreo}

El muestreo se realizó durante una campaña investigativa de seguimiento de la contaminación marina en ría de Vigo (Galicia, NW de España), que incluyó 4 campañas de muestreo, en marzo y octubre de 2004, marzo de 2005, y abril de 2006 (Beiras et al. 2012). El muestreo se realizó en 7 sitios (Fig. 1). Cinco de estos sitios variaron de limpios a moderadamente contaminados y estuvieron localizados desde la parte más externa (BA) hasta la parte más interna (RE) de la ría, 3 de los cuales se encontraban bajo la influencia de las áreas urbanas Cangas (CA), Moaña (MO) y Vigo (AG). Los otros 2 sitios (ViB y ViN) estuvieron localizados en el puerto industrial de Vigo y pueden ser considerados como sitios muy impactados. Los sitios AG, MO y RE fueron visitados durante las 4 campañas, CA y ViB fueron muestreados durante las últimas 3 campañas y $\mathrm{BA}$ y ViN fueron visitados sólo una vez, de tal manera que la base de datos se compuso de 20 puntos de datos.

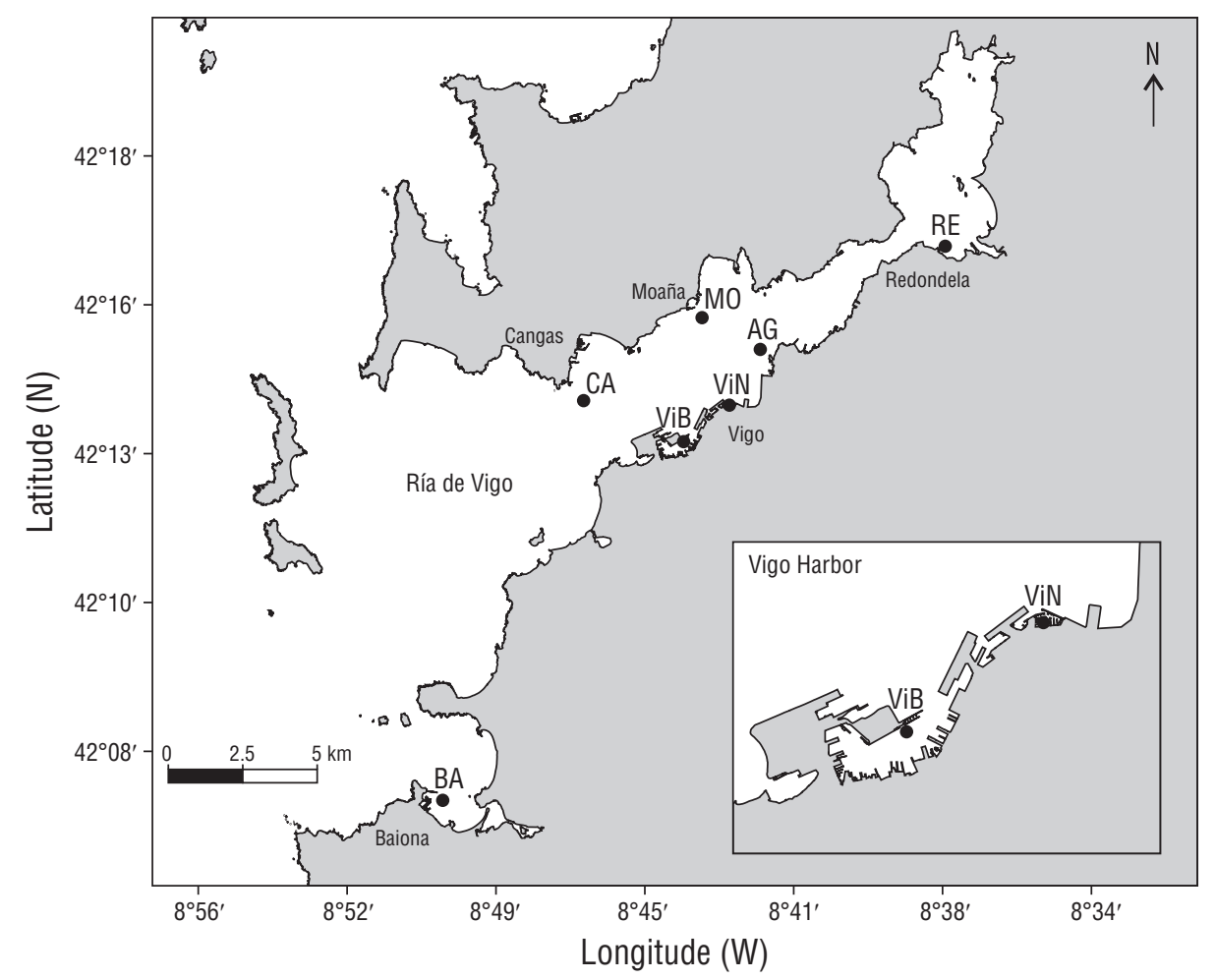

Figure 1. Location of sampling sites (filled circles) at Ría de Vigo (NW Iberian Peninsula).

Figura 1. Localización de los sitios de muestreo (círculos rellenos) en ría de Vigo (NW de la Península Ibérica). 
sampled at 2 depths, at $1 \mathrm{~m}$ beneath the surface (subsurface sample) and at $1 \mathrm{~m}$ above the bottom (bottom sample). When water column depth was $\leq 6 \mathrm{~m}$, only the subsurface sample was taken. All water samples were filtered onboard using $0.45-\mu \mathrm{m}$ polyethersulfone (PES) filters by connecting a flow-through filtering system to the Go-Flo bottle and applying $\mathrm{N}_{2}$ pressure. Filters were collected in triplicate after filtration of $1 \mathrm{~L}$ of water to analyze metals in total particulate matter (TPM). Three more liters were filtered through 3 pre-weighted filters to gravimetrically determine the amount of TPM. Filtered water was collected in high-density polyethylene (HDPE) bottles.

\section{Sample treatment and chemical analyses}

Sediments were sieved through a 2-mm mesh prior to chemical analyses. For metal analyses, sediments (triplicate samples) were digested in microwave with a mixture of $\mathrm{HNO}_{3}-\mathrm{HCl}-\mathrm{HF}$ (Merck Suprapur, Germany). $\mathrm{Cu}$ and Zn were analyzed by flame atomic absorption spectrometry using a Perkin Elmer AAnalyst 800 (USA), and Cd and $\mathrm{Pb}$ were analyzed by electrothermal atomic absorption spectroscopy.

For the analysis of whole mussels, the soft tissues of at least 50 specimens were pooled into a composite sample, homogenized, and freeze-dried. Samples were digested in microwave with $\mathrm{HNO}_{3}$, and metal analysis was performed following the same techniques used for the sediments. The gills of 8 individuals were excised, and $\mathrm{Cd}$, $\mathrm{Cu}, \mathrm{Pb}$, and $\mathrm{Zn}$ were analyzed separately for each individual using inductively coupled plasma mass spectrometry (ICP-MS) (Thermo Elemental; Cheshire, UK) after microwave-assisted digestion of samples with a mixture of $\mathrm{HNO}_{3}$ and $\mathrm{H}_{2} \mathrm{O}_{2}$.

Filters for TPM determination were washed immediately after filtration with $30 \mathrm{~mL}$ of $0.5 \mathrm{M}$ ammonium formate and dried at $90{ }^{\circ} \mathrm{C}$ for $48 \mathrm{~h}$. Filters for analysis of metals in TPM were digested with a mixture of $\mathrm{HNO}_{3}$ and $\mathrm{H}_{2} \mathrm{O}_{2}$, and metals in the acid extract were analyzed by ICP-MS.

Water samples were acidified to $\mathrm{pH} 2$ with $\mathrm{HNO}_{3}$ and subjected to UV-digestion of organic matter. Dissolved metals $(\mathrm{Cd}, \mathrm{Cu}, \mathrm{Pb}$, and $\mathrm{Zn})$ were measured by anodic stripping voltammetry using a polarographic stand (Metrohm 663 VA; Herisau, Switzerland) coupled to an Eco-Chemie AutoLab PGSTAT10 pontentiostat. More details about the analytical procedures are given in Beiras et al. (2012).

All labware in contact with samples were previously soaked in $10 \% \mathrm{HNO}_{3}$ for $24 \mathrm{~h}$ and rinsed with ultrapure water. PES filters were rinsed with $0.2 \% \mathrm{HNO}_{3}$ followed by ultrapure water. HDPE bottles for water samples were additionally rinsed with approximately $100 \mathrm{~mL}$ of filtered water from the sampling site prior to sample collection.

The quality of chemical analyses was subject to a continuous quality assurance system, including the use of
El muestreo de mejillones, agua y sedimento se realizó el mismo día para cada campaña de muestreo. Los mejillones (M. galloprovincialis) de entre 40 y $55 \mathrm{~mm}$ de talla fueron recolectados a mano en la zona infralitoral. Las muestras de agua y sedimento fueron recolectadas a bordo del B/I Navaz (Instituto Español de Oceanografía) con botellas Go-Flo y un nucleador de caja, respectivamente. El agua fue muestreada a 2 profundidades, a $1 \mathrm{~m}$ de la superficie (muestra subsuperficial) y a $1 \mathrm{~m}$ del fondo (muestra de fondo). Cuando la columna de agua era $\leq 6 \mathrm{~m}$, solo se tomó la muestra subsuperficial. Todas las muestras de agua fueron filtradas abordo con filtros de polietersulfona (PES) de $0.45 \mu \mathrm{m}$ conectando un sistema de filtrado de flujo continuo a la botella Go-Flo y aplicando presión de $\mathrm{N}_{2}$. Los filtros fueron recolectados por triplicado después de filtrar $1 \mathrm{~L}$ de agua para el análisis de metales en el material particulado total (MPT). Tres litros adicionales fueron filtrados a través de 3 filtros pesados con anterioridad para la determinación gravimétrica del MPT. El agua filtrada fue recolectada en botellas de polietileno de alta densidad (HDPE, por sus siglas en inglés).

\section{Tratamiento y análisis químico de las muestras}

Los sedimentos fueron tamizados a través de una malla de $2 \mathrm{~mm}$ antes de los análisis químicos. Para los análisis de metales, los sedimentos (muestras triplicadas) fueron digeridos en microondas con una mezcla $\mathrm{HNO}_{3}-\mathrm{HCl}-\mathrm{HF}$ (Merck Suprapur, Alemania). El $\mathrm{Cu}$ y $\mathrm{Zn}$ fueron analizados por espectrometría de absorción atómica con llama usando un AAnalyst 800 de Perkin Elmer (EUA), mientras que el $\mathrm{Cd}$ y $\mathrm{Pb}$ fueron analizados por espectroscopía de absorción atómica electrotérmica.

Para el análisis de mejillones enteros, los tejidos blandos de por lo menos 50 especímenes fueron agrupados en una muestra compuesta, homogeneizados y liofilizados. Las muestras se digirieron en microondas con $\mathrm{HNO}_{3}$, y el análisis de metales se realizó siguiendo las mismas técnicas usadas para los sedimentos. Las branquias de 8 individuos fueron extirpadas, y el $\mathrm{Cd}, \mathrm{Cu}, \mathrm{Pb}$, y $\mathrm{Zn}$ fueron analizados por separado para cada individuo usando la espectrometría de masas con plasma acoplado inductivamente (ICP-MS, por sus siglas en inglés) (Thermo Elemental; Cheshire, Reino Unido) después de la digestión asistida por microondas de las muestras con una mezcla de $\mathrm{HNO}_{3}$ y $\mathrm{H}_{2} \mathrm{O}_{2}$.

Los filtros para la determinación de MPT fueron lavados inmediatamente después de la filtración con $30 \mathrm{~mL}$ de formato de amonio al $0.5 \mathrm{M}$ y secados a $90{ }^{\circ} \mathrm{C}$ por $48 \mathrm{~h}$. Los filtros para el análisis de metales en el MPT fueron digeridos con una mezcla de $\mathrm{HNO}_{3}$ y $\mathrm{H}_{2} \mathrm{O}_{2}$, y los metales en el extracto ácido fueron analizados con ICP-MS.

Las muestras de agua fueron acidificadas a $\mathrm{pH} 2$ con $\mathrm{HNO}_{3}$ y sometidas a la digestión ultravioleta de la materia orgánica. Los metales disueltos $(\mathrm{Cd}, \mathrm{Cu}, \mathrm{Pb}, \mathrm{y} \mathrm{Zn})$ fueron medidos por voltamperometría de redisolución anódica utilizando un soporte polarográfico (Metrohm 663 VA; Herisau, 
duplicate samples, procedural blanks, and certified reference materials (CRM-278 and CRM-414 from the Boureau Communautaire de Reference, EU, for mussel tissues and particulate matter; BCSS- 1 and BEST- 1 from the National Research Council of Canada for sediments; and CRM 403 from the Belgium Community Bureau of Reference for seawater). Adequate analytical performance was also assured by regular participation in international intercomparison exercises, such as Quality Assurance of Information in Marine Environmental Monitoring in Europe (QUASIMEME 2005), with satisfactory Z-scores for each metal reported (Besada et al. 2008).

\section{Data treatment}

Pearson correlation coefficients were used to evaluate the correlation between variables. Despite the majority of variables not being normally distributed (Kolmogorov-Smirnov normality test), logarithmic transformation was not considered necessary because the relationship between untransformed variables did not depart from linearity (Sokal and Rohlf 1995). Multiple regression analysis was performed using IBM SPSS Statistics v24. Partition coefficients were calculated for particulate metals as the ratio between particulate metal concentration $\left(\mu \mathrm{g} \cdot \mathrm{L}^{-1}\right)$ and dissolved metal concentration $\left(\mu \mathrm{g} \cdot \mathrm{L}^{-1}\right)$.

\section{Results}

\section{Metal concentrations in environmental compartments}

Sediments in harbor sites were clearly enriched with metals with respect to the other sites (Table 1). This is especially remarkable for $\mathrm{Cu}$ and $\mathrm{Zn}$, for which no overlapping existed between the concentrations found in non-harbor and harbor sites. The variation ratio (highest to lowest concentration) for all sampled sediments was 40 for $\mathrm{Cu}, 16$ for $\mathrm{Pb}, 29$ for $\mathrm{Zn}$, and 18 for $\mathrm{Cd}$. Metal concentrations in TPM $\left(\mu \mathrm{g} \cdot \mathrm{g}^{-1}\right.$ dry weight $[\mathrm{dw}]$ ) were of the same order of magnitude of those observed in sediments; however, at the sites with the most contaminated sediments, metal concentrations in suspended particles were generally lower than those in sediment particles.

Regarding the water column, $\mathrm{Cu}$ and $\mathrm{Zn}$ concentrations were lower in the particulate phase than in the dissolved phase, with partition coefficients of $0.21 \pm 0.17(n=31)$ for $\mathrm{Cu}$ and $0.27 \pm 0.29(n=30)$ for $\mathrm{Zn}$. Compared to other metals, $\mathrm{Pb}$ showed a higher tendency to be on the particulate phase, with higher partition coefficients $(0.68 \pm 0.61$, $n=32$ ).

$\mathrm{Cu}$ concentrations in sediments correlated with dissolved $\mathrm{Cu}$ concentrations in surface water samples $(r=0.83, P<$ $0.001)$, with particulate $\mathrm{Cu}$ concentrations in surface water samples $(r=0.77, P<0.001)$, and with $\mathrm{Cu}$ concentrations in surface TPM $(r=0.68, P=0.003)$. For the other metals,
Suiza) acoplado a un potenciómetro Eco-Chemie AutoLab PGSTAT10. Los procedimientos analíticos detallados se describen en Beiras et al. (2012).

Todo el material de laboratorio en contacto con las muestras fue sumergido previamente en $\mathrm{HNO}_{3}$ al $10 \%$ por $24 \mathrm{~h}$ y enjuagado con agua ultrapura. Los filtros PES fueron enjuagados primero con $\mathrm{HNO}_{3}$ al $0.2 \%$ y luego con agua ultrapura. Las botellas HDPE para las muestras de agua fueron enjuagadas adicionalmente con aproximadamente $100 \mathrm{~mL}$ de agua filtrada tomada del sitio de muestreo antes de la recolección de la muestra.

La calidad de los análisis químicos fue sometida a un sistema continuo de control de calidad, en el cual se incluyó el uso de las muestras duplicadas, los blancos de procesamiento y los materiales de referencia certificados (CRM-278 y CRM-414 del Bureau Communautaire de Reference, UE, para los tejidos de mejillón y materia particulada; BCSS-1 y BEST-1 del National Research Council, Canadá, para los sedimentos; y CRM 403 del Community Bureau of Reference, Bélgica, para el agua de mar). El desempeño analítico adecuado también fue verificado a través de la participación regular en ejercicios intercomparativos internacionales, como el Quality Assurance of Information in Marine Environmental Monitoring in Europe (QUASIMEME 2005), con puntajes $Z$ satisfactorios reportados para cada metal (Besada et al. 2008).

\section{Tratamiento de datos}

Se usaron los coeficientes de correlación de Pearson para determinar la correlación entre las variables. A pesar de que la mayoría de las variables no se distribuyeron normalmente (prueba de normalidad de Kolmogorov-Smirnov), no se consideró necesaria la transformación logarítmica dado que la relación entre las variables no transformadas no se desviaba de la linearidad (Sokal y Rohlf 1995). El análisis de regresión múltiple se realizó con IBM SPSS Statistics v24. Los coeficientes de partición para el metal particulado fueron calculados como la razón entre la concentración de material particulado $\left(\mu \mathrm{g} \cdot \mathrm{L}^{-1}\right)$ y la concentración de metal disuelto $\left(\mu \mathrm{g} \cdot \mathrm{L}^{-1}\right)$.

\section{RESUltados}

\section{Concentraciones de metales en compartimentos ambientales}

Los sedimentos en los sitios portuarios estaban claramente enriquecidos con metales en comparación con los otros sitios de muestreo (Tabla 1). Esto es especialmente notable para el $\mathrm{Cu}$ y el $\mathrm{Zn}$, para los cuales no existió superposición de concentraciones entre los sitios dentro y fuera del puerto. El cociente de variación (entre la concentración mayor y la menor) para todos los sedimentos muestreados fue de 40 para el $\mathrm{Cu}, 16$ para el $\mathrm{Pb}, 29$ para el $\mathrm{Zn}$ y 18 para el Cd. Las concentraciones de metales en el MPT $\left(\mu \mathrm{g} \cdot \mathrm{g}^{-1}\right.$ peso seco [ps]) fueron del mismo orden de magnitud que aquellas observadas 
Table 1. Range of metal concentrations measured in whole mussel soft tissues $\left(\mathrm{M}_{\text {Mussels }}\right)$ and in abiotic environmental compartments (sediment $\left[\mathrm{M}_{\text {Sed }}\right]$, suspended particles $\left[\mathrm{M}_{\mathrm{TPM}}\right]$, and water column [dissolved $\left(\mathrm{M}_{\text {Dis }}\right)$ and particulate matter $\left.\left(\mathrm{M}_{\text {Part }}\right)\right]$ ) at the sampling sites during the study period. Sites are grouped according to their location, outside (non-harbor sites) or inside (harbor sites) Vigo Harbor. Codes for sampling sites are described in the main text. Dry weight (dw); not applicable (n.a.).

Tabla 1. Rango de las concentraciones de metales medidas en los tejidos blandos de los mejillones $\left(\mathrm{M}_{\mathrm{Mussels}}\right)$ y en los compartimentos ambientales (sedimentos $\left[\mathrm{M}_{\text {Sed }}\right]$; partículas suspendidas, $\left[\mathrm{M}_{\mathrm{TPM}}\right]$; y columna de agua [materia disuelta $\left(\mathrm{M}_{\mathrm{Dis}}\right)$ y particulada $\left.\left(\mathrm{M}_{\text {Part }}\right)\right]$ ) en los sitios de muestreo durante el periodo de estudio. Los sitios están agrupados según su localización, fuera (sitios no portuarios [non-harbor sites]) o dentro (sitios portuarios [harbor sites]) del puerto de Vigo. Los códigos para los sitios de muestreo se describen en el texto general. Peso seco (dw); no aplica (n.a.).

\begin{tabular}{|c|c|c|c|c|c|c|c|}
\hline & \multicolumn{5}{|c|}{ Non-harbor sites } & \multicolumn{2}{|c|}{ Harbor sites } \\
\hline & BA & $\mathrm{CA}$ & MO & AG & $\mathrm{RE}$ & ViB & $\mathrm{ViN}$ \\
\hline \multicolumn{8}{|c|}{$\mathrm{M}_{\text {Mussels }}\left(\mu \mathrm{g} \cdot \mathrm{g}^{-1} \mathrm{dw}\right)$} \\
\hline $\mathrm{Cd}$ & 0.53 & $0.66-0.73$ & $0.57-0.77$ & $0.50-0.77$ & $0.55-0.61$ & $0.57-1.2$ & 1.0 \\
\hline $\mathrm{Cu}$ & 7.5 & $4.5-6.6$ & $5.4-7.6$ & $5.9-9.3$ & $4.1-9.9$ & $33-109$ & 59 \\
\hline $\mathrm{Pb}$ & 2.0 & $2.0-2.5$ & $2.1-3.0$ & $3.7-4.5$ & $4.0-4.7$ & $3.9-15$ & 7.5 \\
\hline $\mathrm{Zn}$ & 217 & $266-393$ & $213-271$ & $257-270$ & $230-290$ & $342-369$ & 411 \\
\hline \multicolumn{8}{|c|}{$\mathrm{M}_{\mathrm{Sed}}\left(\mu \mathrm{g} \cdot \mathrm{g}^{-1} \mathrm{dw}\right)$} \\
\hline $\mathrm{Cd}$ & 0.15 & $0.08-0.17$ & $0.20-0.44$ & $0.46-0.52$ & $0.53-0.70$ & $0.70-1.4$ & 0.64 \\
\hline $\mathrm{Cu}$ & 9.3 & $29-37$ & $44-49$ & $70-83$ & $51-55$ & $199-363$ & 367 \\
\hline $\mathrm{Pb}$ & 18.5 & $67-78$ & $45-110$ & 63-139 & $112-185$ & $117-217$ & 305 \\
\hline $\mathrm{Zn}$ & 53 & $127-180$ & $144-177$ & $216-264$ & $157-190$ & $510-1530$ & 299 \\
\hline \multicolumn{8}{|c|}{$\mathrm{M}_{\mathrm{TPM}}\left(\mu \mathrm{g} \cdot \mathrm{g}^{-1} \mathrm{dw}\right)$} \\
\hline $\mathrm{Cd}$ & n.a. & $0.17-0.62$ & $0.12-0.40$ & $0.18-1.3$ & $0.24-0.42$ & $0.17-0.63$ & 0.19 \\
\hline $\mathrm{Cu}$ & n.a. & $17-93$ & $29-83$ & $36-145$ & $29-85$ & $32-518$ & 69 \\
\hline $\mathrm{Pb}$ & n.a. & $19-78$ & $29-70$ & $32-148$ & $51-180$ & 29-102 & 56 \\
\hline $\mathrm{Zn}$ & n.a. & $38-555$ & $50-580$ & $91-543$ & 94-192 & $133-556$ & 166 \\
\hline \multicolumn{8}{|c|}{$\mathrm{M}_{\text {Part }}\left(\mu \mathrm{g} \cdot \mathrm{L}^{-1}\right)^{\mathrm{a}}$} \\
\hline $\mathrm{Cd}$ & n.a. & $0.40-1.4$ & $0.27-0.61$ & $0.45-3.1$ & $0.55-0.93$ & $0.33-0.69$ & 0.49 \\
\hline $\mathrm{Cu}$ & n.a. & $0.04-0.15$ & $0.06-0.27$ & $0.09-1.1$ & $0.08-0.13$ & $0.07-0.58$ & 0.18 \\
\hline $\mathrm{Pb}$ & n.a. & $0.05-0.14$ & $0.06-0.17$ & $0.08-1.1$ & $0.16-0.24$ & $0.06-0.19$ & 0.15 \\
\hline $\mathrm{Zn}$ & n.a. & $0.09-0.97$ & $0.10-1.1$ & $0.16-1.8$ & $0.25-0.37$ & $0.29-1.4$ & 0.43 \\
\hline \multicolumn{8}{|c|}{$\mathrm{M}_{\mathrm{Dis}}\left(\mu \mathrm{g} \cdot \mathrm{L}^{-1}\right)$} \\
\hline $\mathrm{Cd}$ & $<0.01^{\mathrm{b}}$ & $<0.01^{\mathrm{b}}$ & $<0.01^{\mathrm{b}}-0.5$ & $<0.01^{\mathrm{b}}$ & $<0.01^{\mathrm{b}}$ & $<0.01^{\mathrm{b}}$ & 0.07 \\
\hline $\mathrm{Cu}$ & $0.17-0.46$ & $0.27-1.6$ & $0.22-1.0$ & $0.32-1.3$ & $0.37-1.2$ & $0.51-17$ & 2.9 \\
\hline $\mathrm{Pb}$ & $0.10-0.19$ & $0.16-0.6$ & $0.1-0.4$ & $0.09-0.49$ & $0.11-1.6$ & $0.11-0.93$ & 0.14 \\
\hline $\mathrm{Zn}$ & $0.77-2.4$ & $0.74-4.1$ & $0.79-4.5$ & $1.2-3.7$ & $0.4-20$ & $1.6-48$ & 6.5 \\
\hline
\end{tabular}

${ }^{\mathrm{a}}$ Except $\mathrm{Cd}$ concentrations, which are expressed in $\mathrm{ng} \cdot \mathrm{L}^{-1}$.

${ }^{\mathrm{b}}$ Detection limit for dissolved Cd. 
the only correlations observed were between metal concentrations in surface and bottom TPM. In general, the results showed a high degree of variation and different patterns regarding metals in sediment, water, and particulate matter, so the 3 compartments may have different relationships with metal bioaccumulation in filter feeding organisms.

\section{Metal concentrations in whole soft tissues and gills}

Regarding whole mussel soft tissues, Cd concentrations were quite homogeneous throughout the sites, being only slightly higher at $\mathrm{ViB}$ and $\mathrm{ViN}$ (Table 1). $\mathrm{Cu}$ concentrations ranged from 4 to $10 \mu \mathrm{g} \cdot \mathrm{g}^{-1} \mathrm{dw}$ at all stations located outside harbors, while at the 2 sites in Vigo Harbor $\mathrm{Cu}$ concentrations (33-109 $\mu \mathrm{g} \cdot \mathrm{g}^{-1} \mathrm{dw}$ ) were about one order of magnitude higher than at the other sites. $\mathrm{Pb}$ concentrations were higher at the harbor sites $\left(4-15 \mu \mathrm{g} \cdot \mathrm{g}^{-1} \mathrm{dw}\right)$ and at the inner stations (RE and $\mathrm{AG}, \sim 4 \mu \mathrm{g} \cdot \mathrm{g}^{-1} \mathrm{dw}$ ) than at the other locations, where $\mathrm{Pb}$ concentrations were between 2 and $3 \mu \mathrm{g} \cdot \mathrm{g}^{-1} \mathrm{dw}$. The highest $\mathrm{Zn}$ concentrations were also observed in whole soft tissues of mussels from the harbor sites, followed by CA, although the difference with the least contaminated sites was not very high ( $\sim 1.5$ times) (Table 1$)$.

In general, metal concentrations in gills were within the same order of magnitude as those found in whole soft tissues, although deviations from the 1:1 line were observed for all metals except $\mathrm{Pb}$ (Fig. 2). Pb concentrations were very similar for gills and whole soft tissues along the pollution gradient. In the case of $\mathrm{Cu}$, the deviation from the 1:1 line was not very high in low to moderately polluted places, while at harbor sites, $\mathrm{Cu}$ concentrations were up to 5 times higher in gills than in whole soft tissues. It is remarkable that $\mathrm{Zn}$ in mussel gills was virtually constant around $60 \mu \mathrm{g} \cdot \mathrm{g}^{-1} \mathrm{dw}$ along a $\mathrm{Zn}$ gradient in whole mussel soft tissue (from 200 to $400 \mu \mathrm{g} \cdot \mathrm{g}^{-1} \mathrm{dw}$ ), except for a single sample point (ViB-1004), for which $\mathrm{Zn}$ concentrations in gills reached the same concentration observed in whole mussel soft tissues. A similar pattern was observed for $\mathrm{Cd}$, showing lower values in gills (around $0.2 \mu \mathrm{g} \cdot \mathrm{g}^{-1} \mathrm{dw}$ ) than in whole soft tissues $\left(0.5-1.2 \mu \mathrm{g} \cdot \mathrm{g}^{-1} \mathrm{dw}\right)$, with only 1 site (ViB-1004) showing higher $\mathrm{Cd}$ concentrations in gills. Significant correlations were observed between metal concentrations in gills and those in whole mussel soft tissues for $\mathrm{Cu}(r=0.936, P<0.001)$ and $\mathrm{Pb}(r=0.889, P<$ 0.001), but not for $\mathrm{Zn}$ and $\mathrm{Cd}$.

\section{Comparison of metal bioaccumulation with environmental compartments}

No significant correlations were found between bioaccumulated $\mathrm{Cd}$ and $\mathrm{Cd}$ concentrations in any of the abiotic environmental compartments analyzed. $\mathrm{Cu}$ concentrations in whole mussel soft tissues correlated with $\mathrm{Cu}$ concentrations in sediments, with $\mathrm{Cu}$ concentrations in TPM collected from both surface and bottom waters, and with en los sedimentos; sin embargo, en los sitios con los sedimentos más contaminados, las concentraciones de metales en las partículas suspendidas fueron generalmente más bajas que aquellas en las partículas del sedimento.

Con respecto a la columna de agua, las concentraciones de $\mathrm{Cu}$ y $\mathrm{Zn}$ fueron más bajas en la fase particulada que en la fase disuelta, con coeficientes de partición de $0.21 \pm 0.17(n=31)$ para el $\mathrm{Cu}$ y $0.27 \pm 0.29(n=30)$ para el $\mathrm{Zn}$. Comparado con otros metales, el $\mathrm{Pb}$ mostró una mayor tendencia a estar en la fase particulada, con coeficientes de partición más altos $(0.68 \pm 0.61, n=32)$.

La concentración de $\mathrm{Cu}$ en los sedimentos se correlacionó con las concentraciones de $\mathrm{Cu}$ disuelto en las muestras de agua superficial $(r=0.83, P<0.001)$, con las concentraciones de $\mathrm{Cu}$ particulado en las muestras de agua superficial $(r=0.77, P<0.001)$, y con las concentraciones de $\mathrm{Cu}$ en el MPT en superficie $(r=0.68, P=0.003)$. Para los otros metales, la única correlación observada fue entre las concentraciones de metales en el MPT en superficie y en el fondo. En general, los resultados mostraron un alto grado de variación y patrones distintos con respecto al sedimento, agua y materia particulada, por lo que es posible que los 3 compartimentos tengan relaciones diferentes con la bioacumulación de metales en organismos filtradores.

\section{Concentraciones de metales en tejidos blandos enteros y branquias de mejillón}

Con respecto a los tejidos enteros de mejillón, las concentraciones de $\mathrm{Cd}$ fueron bastante homogéneas en todos los sitios, apenas un poco más altas en $\mathrm{ViB}$ y ViN (Tabla 1). Las concentraciones de $\mathrm{Cu}$ oscilaron entre 4 y $10 \mu \mathrm{g} \cdot \mathrm{g}^{-1} \mathrm{ps}$ en todos los sitios fuera de los puertos, mientras que en los 2 sitios dentro del puerto de Vigo las concentraciones de $\mathrm{Cu}\left(33-109 \mu \mathrm{g} \cdot \mathrm{g}^{-1} \mathrm{ps}\right)$ fueron aproximadamente un orden de magnitud mayores que en los otros sitios. Las concentraciones de $\mathrm{Pb}$ fueron mayores en los sitios portuarios $\left(4-15 \mu \mathrm{g} \cdot \mathrm{g}^{-1} \mathrm{ps}\right) \mathrm{y}$ en las estaciones interiores (RE y $\mathrm{AG}, \sim 4 \mu \mathrm{g} \cdot \mathrm{g}^{-1} \mathrm{ps}$ ) que en los otros sitios, donde las concentraciones de $\mathrm{Pb}$ fueron de entre 2 y $3 \mu \mathrm{g} \cdot \mathrm{g}^{-1} \mathrm{ps}$. Las concentraciones de $\mathrm{Zn}$ más altas también fueron observadas en los tejidos blandos enteros de los mejillones de los sitios portuarios, seguidos por CA, aunque la diferencia con los sitios menos contaminados no fue muy grande ( $\sim 1.5$ veces $)$ (Tabla 1).

En general, las concentraciones de metales en las branquias fueron del mismo orden de magnitud que aquellas encontradas en los tejidos blandos enteros, aunque las desviaciones con respecto a la línea 1:1 fueron observadas para todos los metales excepto para el Pb (Fig. 2). Las concentraciones de $\mathrm{Pb}$ fueron muy similares entre las branquias y los tejidos blandos enteros a lo largo del gradiente de contaminación. En el caso del $\mathrm{Cu}$, la desviación con respecto a la línea 1:1 no fue muy grande en los sitios poco contaminados o de contaminación moderada, 

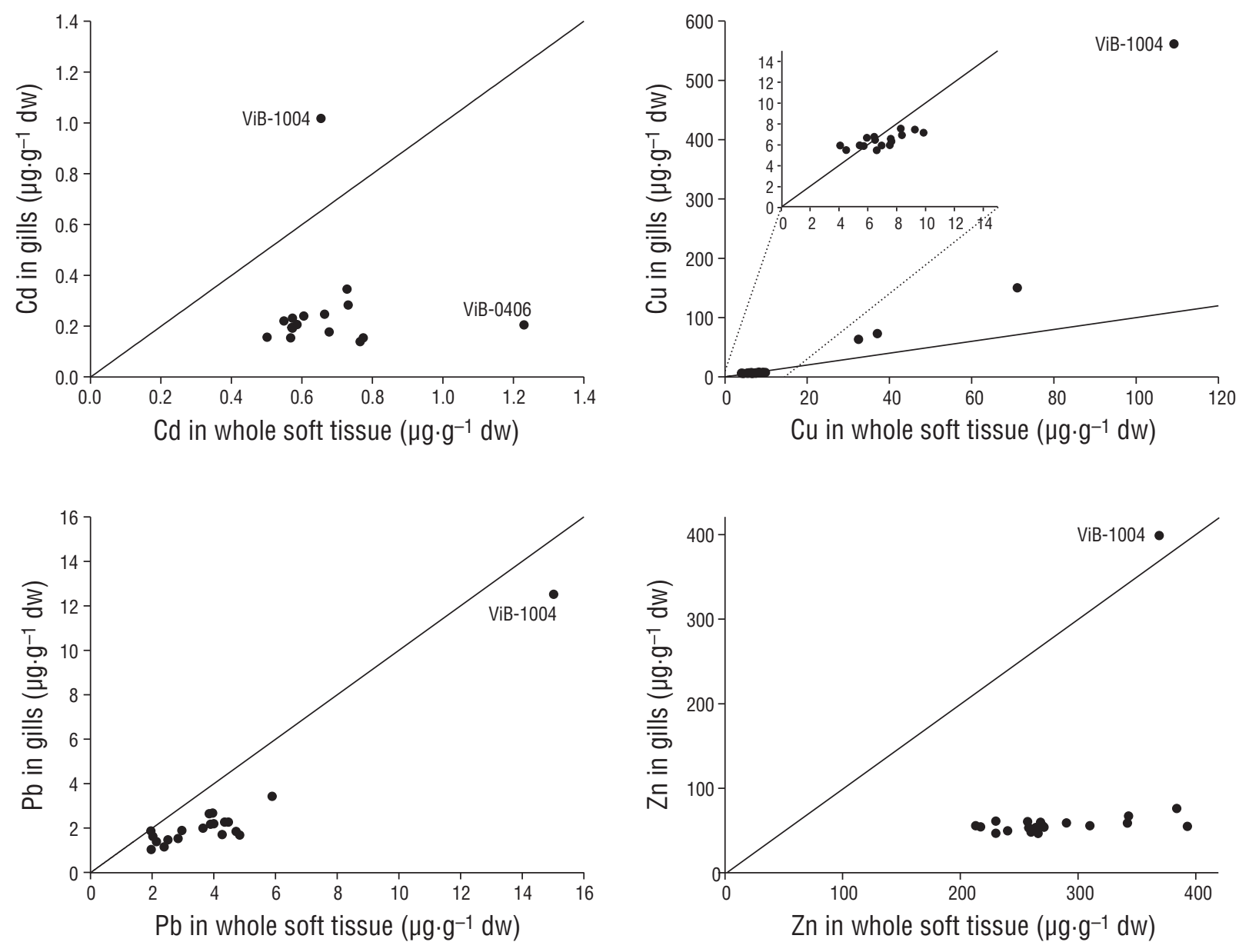

Figure 2. Relationship between metal concentration in gills and in whole soft tissues of Mytilus galloprovincialis mussels. Straight line represents the 1:1 relationship. Sampling points ViB-1004 and ViB-0406 are identified.

Figura 2. Relación entre la concentración de metales en las branquias y el tejido blando entero de los mejillones Mytilus galloprovincialis. La línea recta representa la relación 1:1. Se identifican los puntos de muestreo ViB-1004 y ViB-0406.

dissolved $\mathrm{Cu}$ in bottom waters (Table 2). Interestingly, ViB in the October 2004 survey (ViB-1004) showed the highest $\mathrm{Cu}$ concentration in mussels, especially in mussel gills, but it was not the sampling point with the highest $\mathrm{Cu}$ concentration in sediments (Fig. 3). However, it was the sampling point with the highest dissolved $\mathrm{Cu}$ concentration in bottom waters (Fig. 3) and in TPM in bottom waters $\left(518 \mu \mathrm{g} \cdot \mathrm{g}^{-1}\right.$, followed by $163 \mu \mathrm{g} \cdot \mathrm{g}^{-1}$ in ViB-0305). It seems that some process occurred at that point during this survey that provoked an increase in $\mathrm{Cu}$ concentrations in the water column that was in turn reflected in mussel gills and, to a lesser extent, in whole mussel soft tissues. If this point is excluded from the correlation analysis, $\mathrm{Cu}$ concentrations in whole mussel soft tissue no longer correlate with dissolved $\mathrm{Cu}$ concentrations in bottom waters and $\mathrm{Cu}$ concentrations in TPM, although the correlation with $\mathrm{Cu}$ concentrations in sediments is maintained (Table 2). Apparently, at up to $100 \mu \mathrm{g} \cdot \mathrm{g}^{-1}$ of $\mathrm{Cu}$ in sediments, mussels were able to maintain $\mathrm{Cu}$ concentrations mientras que en los sitios portuarios las concentraciones de $\mathrm{Cu}$ fueron hasta 5 veces más elevadas en las branquias que en los tejidos blandos enteros. Es notable que el $\mathrm{Zn}$ en las branquias de mejillón se mantuvo prácticamente constante alrededor de $60 \mu \mathrm{g} \cdot \mathrm{g}^{-1} \mathrm{ps}$ a lo largo de un gradiente del $\mathrm{Zn}$ en los tejidos blandos enteros de mejillón (de $200 \mathrm{a}$ $400 \mu \mathrm{g} \cdot \mathrm{g}^{-1} \mathrm{ps}$ ), a excepción de un único punto de muestreo (ViB-1004), donde las concentraciones de $\mathrm{Zn}$ en las branquias alcanzaron la misma concentración observada en los tejidos blandos enteros de mejillón. Se observó un patrón similar para el $\mathrm{Cd}$, donde las concentraciones fueron más bajas en las branquias (alrededor de $0.2 \mu \mathrm{g} \cdot \mathrm{g}^{-1} \mathrm{ps}$ ) que en los tejidos blandos enteros $\left(0.5-1.2 \mu \mathrm{g} \cdot \mathrm{g}^{-1} \mathrm{ps}\right)$ y solo en un sitio (ViB-1004) las concentraciones fueron más altas en las branquias. Se observaron correlaciones significativas entre las concentraciones de metales en las branquias y las concentraciones de metales en los tejidos blandos enteros de mejillón para el $\mathrm{Cu}(r=0.936, P<0.001)$ y el $\mathrm{Pb}(r=0.889$, $P<0.001$ ), pero no para el $\mathrm{Zn}$ y el $\mathrm{Cd}$. 
at stable levels, below $10 \mu \mathrm{g} \cdot \mathrm{g}^{-1} \mathrm{dw}$ (Fig. 3). However, at harbor sites, where $\mathrm{Cu}$ concentrations in sediments were markedly higher, $\mathrm{Cu}$ bioaccumulation increased, probably due to a loss in the regulation ability of mussels to maintain constant body $\mathrm{Cu}$ concentrations at these high levels, as will be discussed later. If the data points corresponding to harbor sites $(\mathrm{Cu}$ concentrations in sediments greater than $100 \mu \mathrm{g} \cdot \mathrm{g}^{-1}$ ) are excluded from the analysis, $\mathrm{Cu}$ concentrations in whole mussel soft tissues no longer correlate with $\mathrm{Cu}$ concentrations in sediments, although concentrations in mussel gills still do (Table 2).

In the case of $\mathrm{Pb}$, there was no correlation between $\mathrm{Pb}$ in tissues and $\mathrm{Pb}$ in sediments, because of the same outstanding point, ViB-1004, which showed the highest $\mathrm{Pb}$ concentration in mussel tissues but an intermediate concentration in sediments (Fig. 3, Table 2). If this point is excluded from the analysis, a significant correlation is observed between bioaccumulated $\mathrm{Pb}$ (both in gills and in whole soft tissues) and $\mathrm{Pb}$ in sediments. On the contrary, if $\mathrm{Pb}$ concentration in tissues is compared to $\mathrm{Pb}$ concentration in bottom waters, a significant correlation is observed due to the data associated with ViB-1004, but if this point is excluded, the correlation is lost (Table 2). A high $\mathrm{Pb}$ concentration was observed at this station and sampling time both in mussels and in bottom waters (dissolved), but this was not reflected in sediment concentrations, which were more stable and did not show high fluctuations with the time of sampling (Fig. 3).

For $\mathrm{Zn}$, a significant but weak correlation $(r=0.46, P=$ $0.043, n=20$ ) was found between $\mathrm{Zn}$ in whole soft tissues and $\mathrm{Zn}$ in sediments when all data were included. On the contrary, the correlation for $\mathrm{Zn}$ in mussel gills was not significant when all points were included, but when the data associated with ViB-1004 were excluded, a significant correlation was observed between $\mathrm{Zn}$ in mussel gills and $\mathrm{Zn}$ in sediments $(r=0.58, P=0.012, n=18)$. This was because the $\mathrm{Zn}$ concentration in gills was about one order of magnitude higher for this sampling point compared to all others, but ViB-1004 was not the sampling point reflecting the highest concentration in sediments. Zn concentrations in bottom waters were in agreement with the pattern observed for $\mathrm{Zn}$ in mussel gills, with $\mathrm{Zn}$ concentrations about one order of magnitude higher at ViB-1004 than those at the other points (Fig. 3). A significant correlation was found between $\mathrm{Zn}$ in mussel gills and $\mathrm{Zn}$ dissolved in bottom waters $(r=0.99, P<0.001, n=15)$, due to the same sampling point (Table 2).

Multiple regressions were done with all data to analyze if metal bioaccumulation could be better modeled using a combination of variables. $\mathrm{Cu}$ in whole soft tissues and $\mathrm{Cu}$ in mussel gills were well predicted using both dissolved $\mathrm{Cu}$ in bottom waters and $\mathrm{Cu}$ in sediments (Table 3 ). The same occurred for $\mathrm{Pb}$ in whole soft tissues, which was well modeled using dissolved $\mathrm{Pb}$ in bottom waters and $\mathrm{Pb}$ in sediments. On the contrary, modeling of $\mathrm{Pb}$ in mussel gills did

\section{Comparación de la bioacumulación de metales entre compartimentos ambientales}

No se encontraron correlaciones significativas en las concentraciones de $\mathrm{Cd}$ bioacumulado y el $\mathrm{Cd}$ en los compartimentos abióticos analizados. Las concentraciones de $\mathrm{Cu}$ en los tejidos blandos enteros de mejillón se correlacionaron con las concentraciones de $\mathrm{Cu}$ en los sedimentos, con las concentraciones de $\mathrm{Cu}$ en el MPT recolectado tanto en la superficie como en el agua del fondo y con el $\mathrm{Cu}$ disuelto en el agua del fondo (Tabla 2). De manera interesante, ViB en la campaña de octubre de 2004 (ViB-1004) mostró la concentración de $\mathrm{Cu}$ más alta en mejillones, especialmente en las branquias, pero no fue el punto de muestreo con la concentración de $\mathrm{Cu}$ más alta en los sedimentos (Fig. 3). Sin embargo, sí fue el punto de muestreo con la concentración de Cu disuelto más alta en el agua del fondo (Fig. 3) y en el MPT del agua del fondo (518 $\mu \mathrm{g} \cdot \mathrm{g}^{-1}$, seguido por $163 \mu \mathrm{g} \cdot \mathrm{g}^{-1}$ en ViB-0305). Al parecer, hubo algún proceso en ese punto durante esa campaña que provocó un incremento en las concentraciones de $\mathrm{Cu}$ en la columna de agua que a su vez se reflejó en las branquias de mejillón y, en menor grado, en los tejidos blandos enteros de mejillón. Si se excluye este punto del análisis de correlación, las concentraciones de $\mathrm{Cu}$ en los tejidos blandos de mejillón ya no se correlacionan con las concentraciones de $\mathrm{Cu}$ disuelto en el agua del fondo ni con las concentraciones de $\mathrm{Cu}$ en el TPM, aunque se mantiene la correlación con las concentraciones de $\mathrm{Cu}$ en los sedimentos (Tabla 2). Aparentemente, a hasta $100 \mu \mathrm{g} \cdot \mathrm{g}^{-1}$ de $\mathrm{Cu}$ en los sedimentos, los mejillones fueron capaces de mantener las concentraciones corporales de $\mathrm{Cu}$ a niveles estables, por debajo de $10 \mu \mathrm{g} \cdot \mathrm{g}^{-1}$ ps (Fig. 3). Sin embargo, en los sitios portuarios, donde las concentraciones de $\mathrm{Cu}$ en los sedimentos fueron marcadamente más elevadas, la bioacumulación de $\mathrm{Cu}$ aumentó, probablemente debido a la pérdida de la capacidad de regulación de los mejillones para mantener concentraciones corporales constantes a estos niveles altos, como se discutirá luego. Si los datos puntuales correspondientes a los sitios portuarios (concentraciones de $\mathrm{Cu}$ en los sedimentos mayores que $\left.100 \mu \mathrm{g} \cdot \mathrm{g}^{-1}\right) \mathrm{se}$ excluyen del análisis, las concentraciones de $\mathrm{Cu}$ en los tejidos blandos enteros de mejillón ya no se correlacionan con las concentraciones de $\mathrm{Cu}$ en los sedimentos, aunque las concentraciones en las branquias de mejillón sí mantienen la correlación (Tabla 2).

En el caso del $\mathrm{Pb}$, no hubo una correlación entre el $\mathrm{Pb}$ en los tejidos y el $\mathrm{Pb}$ en los sedimentos debido al mismo punto destacado, ViB-1004, el cual mostró la concentración de $\mathrm{Pb}$ más alta en los tejidos de mejillón, pero una concentración intermedia en los sedimentos (Fig. 3, Tabla 2). Si este punto se excluye del análisis, se observa una correlación significativa entre el $\mathrm{Pb}$ bioacumulado (tanto en las branquias como en los tejidos blandos enteros) y el $\mathrm{Pb}$ en sedimentos. Por el contrario, si la concentración de $\mathrm{Pb}$ en los tejidos se compara con la concentración de $\mathrm{Pb}$ en el agua del fondo, se observa una correlación significativa debido a los datos 


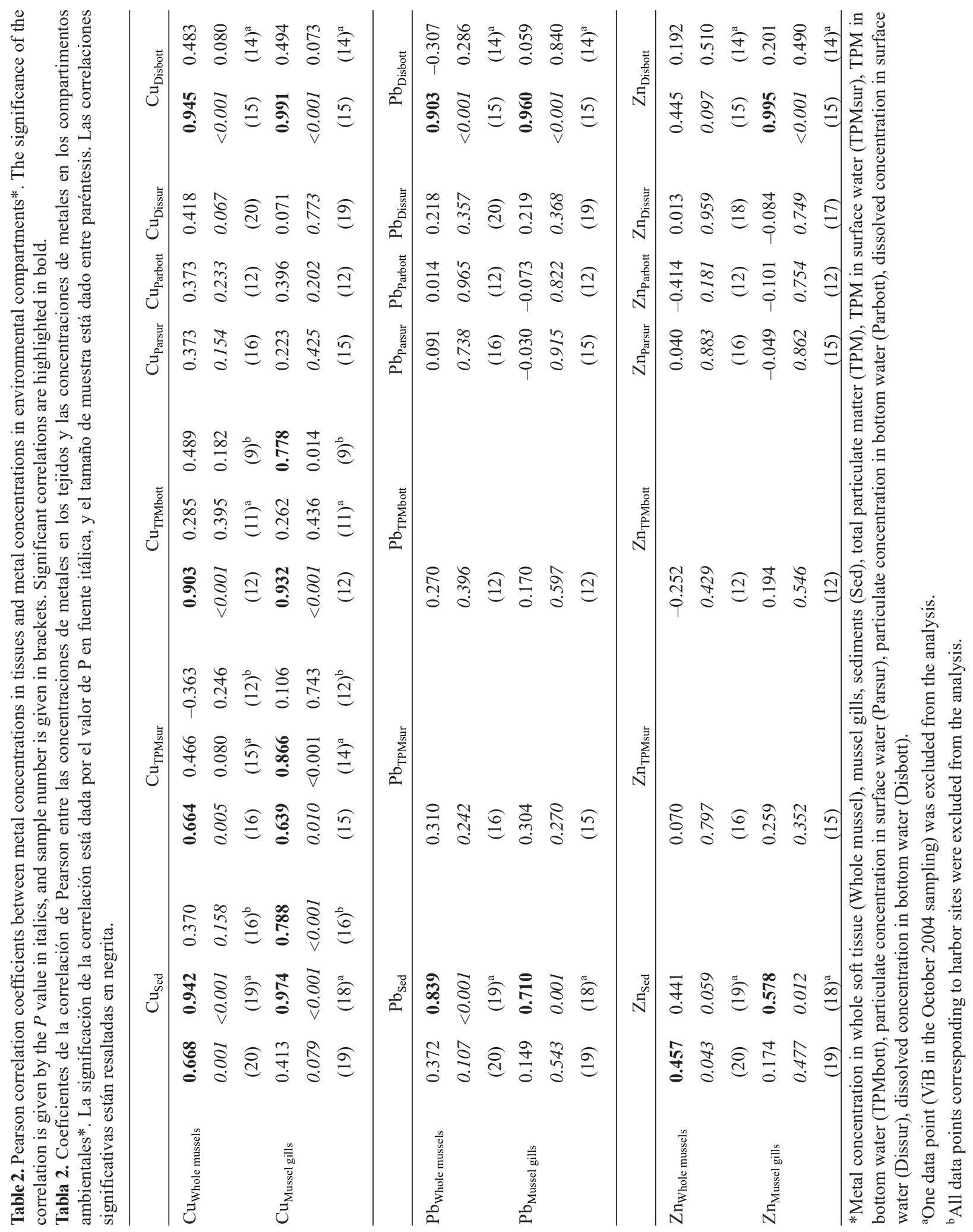



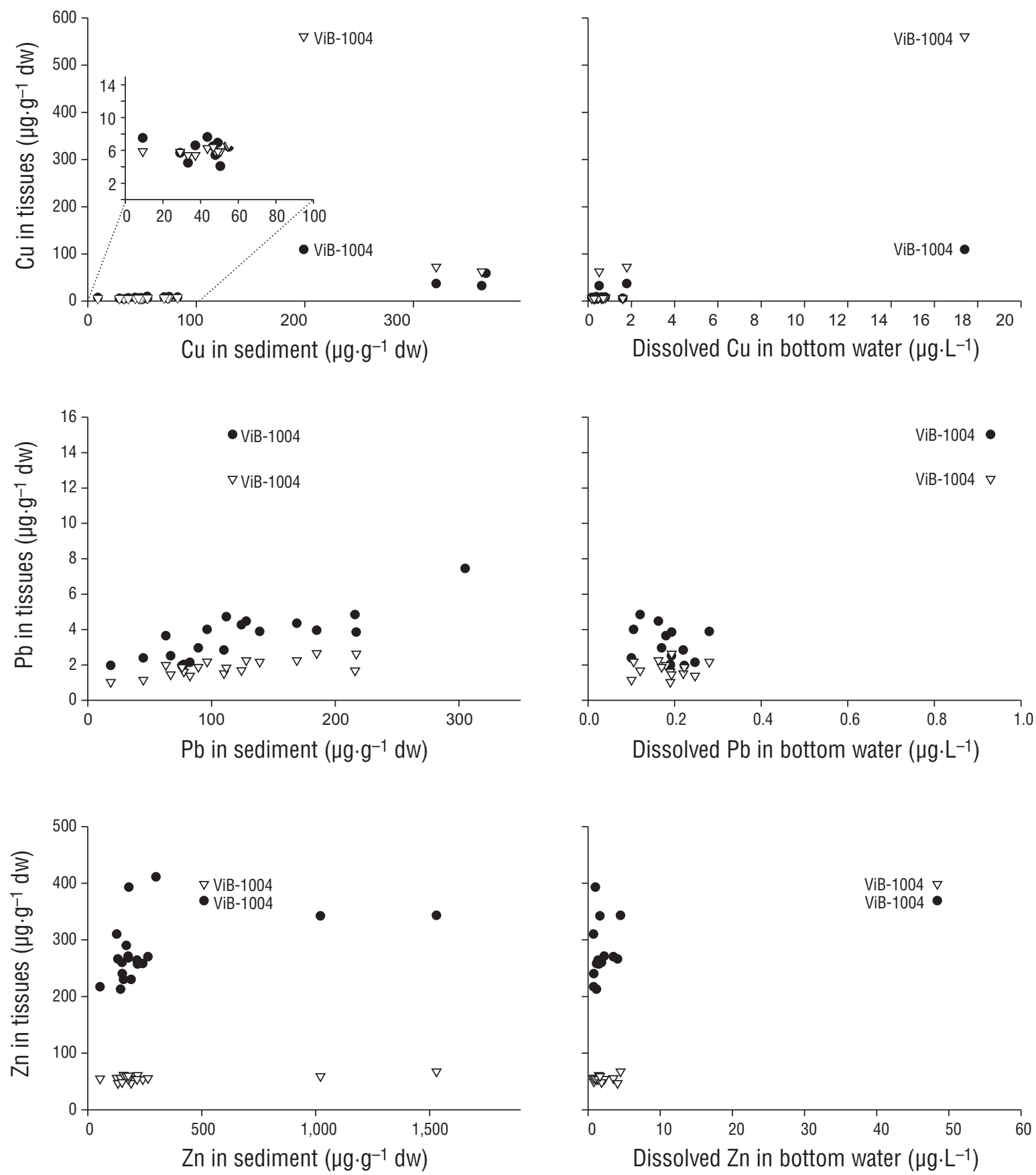

- Mussel whole soft tissue $\quad \nabla$ Mussel gills

Figure 3. Relationships between metal concentrations in tissues (whole soft mussel tissues and mussel gills) and environmental concentrations in sediment (left panel) and dissolved metal in bottom waters (right panel). The ViB-1004 sampling point is identified

Figura3. Relaciones entre las concentraciones de metales en los tejidos (tejidos blandos enteros y branquias de mejillones) y las concentraciones ambientales en el sedimento (panel izquierdo) y el metal disuelto en aguas de fondo (panel derecho). Se identifica el punto de muestreo ViB-1004. 
not improve by using 2 variables, dissolved $\mathrm{Pb}$ in bottom waters being the best predictor alone. In the case of $\mathrm{Zn}, \mathrm{Zn}$ in whole soft tissues was best predicted by $\mathrm{Zn}$ concentrations in sediments, and $\mathrm{Zn}$ in mussel gills was best predicted by dissolved $\mathrm{Zn}$ concentrations in bottom waters (Table 2); no significant improvement was achieved with the use of an additional variable.

\section{Discussion}

Mussels can regulate their internal $\mathrm{Cu}$ concentrations within a certain limit (Amiard et al. 1987, Lorenzo et al. 2003, Lorenzo et al. 2005), but at very high $\mathrm{Cu}$ concentrations in the environment, this regulation capacity is lost. Because of this, correlations between $\mathrm{Cu}$ concentrations in mussels and $\mathrm{Cu}$ concentrations in environmental compartments such as sediments are usually difficult to find (Langston and Spence 1995, Hummel et al. 1997, Przytarska et al. 2010) unless very high levels of $\mathrm{Cu}$ pollution are reached (Beiras et al. 2003b), as observed in the present study. This has raised questions about the usefulness of mussels in $\mathrm{Cu}$ pollution monitoring, and the use of other filter-feeding species such as oysters has been proposed, given that oysters apparently lack any regulatory ability for $\mathrm{Cu}$ (Cooper et al. 1982, Lorenzo et al. 2003). Mussel gills seem to be a suitable complement for $\mathrm{Cu}$ biomonitoring because they seem to respond more quickly to environmental changes in $\mathrm{Cu}$ concentrations than do the rest of the mussel tissues (Sánchez-Marín et al. 2016). This is well exemplified by the data from the ViB-1004 sampling point, where an increase in dissolved $\mathrm{Cu}$ of about an order of magnitude compared to the other sampling points was directly reflected by a one-order-of-magnitude increase of $\mathrm{Cu}$ in gills, but in the whole body this increase was much smaller (Fig. 3). Also, at low to moderately polluted sites, with less than $100 \mu \mathrm{g} \cdot \mathrm{g}^{-1}$ of $\mathrm{Cu}$ in sediments, gills performed better than whole mussel soft tissue in reflecting environmental variability in $\mathrm{Cu}$ concentrations. $\mathrm{Cu}$ in mussel gills correlated with $\mathrm{Cu}$ in sediments even when harbor locations were excluded from the analysis (Table 2), while whole mussel soft tissues at all sites outside harbors showed similar $\mathrm{Cu}$ concentrations.

In the case of $\mathrm{Pb}$, both gills and whole organisms showed very similar relationships with abiotic environmental compartments, and their $\mathrm{Pb}$ concentrations were very similar, closely following a 1:1 relationship even at the most polluted sites (Fig. 2). Laboratory experiments showed a rapid distribution of $\mathrm{Pb}$ within mussel tissues. In a study on dissolved $\mathrm{Pb}$ uptake kinetics, $\mathrm{Pb}$ concentrations in gills and rest of tissues were similar in all time points (from 1 to 24 h) (Sánchez-Marín et al. 2011). The high Pb concentration at ViB-1004, both in mussels and in the dissolved phase, reveals that mussels are reflecting a real-and probably recent-increase in the concentration of bioavailable $\mathrm{Pb}$, even though this is not reflected in the sediments. Sediments asociados con ViB-1004, pero si se excluye este punto, se pierde la correlación (Tabla 2). Se observó una alta concentración de $\mathrm{Pb}$ en esta estación y en ese tiempo de muestreo tanto en los mejillones como en el agua del fondo (concentración disuelta), pero esto no se reflejó en las concentraciones en los sedimentos, las cuales fueron más estables y no mostraron altas fluctuaciones con el tiempo de muestreo (Fig. 3).

Para el Zn, se encontró una correlación significativa pero débil $(r=0.46, P=0.043, n=20)$ entre el $\mathrm{Zn}$ en los tejidos blandos enteros de mejillón y el $\mathrm{Zn}$ en los sedimentos cuando se incluyeron todos los datos. Por lo contrario, para el $\mathrm{Zn}$ en las branquias de mejillón, la correlación no fue significativa cuando se incluyeron todos los datos, pero cuando se excluyeron los datos asociados a ViB-1004, se encontró una correlación significativa entre el $\mathrm{Zn}$ en las branquias y el $\mathrm{Zn}$ en los sedimentos $(r=0.58, P=0.012, n=18)$. Esto se debe a que la concentración de $\mathrm{Zn}$ en las branquias fue un orden de magnitud más alta para este punto de muestreo (ViB-1004) comparado con todos los otros, aunque este no fue el punto de muestreo que reflejó la concentración más alta en los sedimentos. Las concentraciones de $\mathrm{Zn}$ en el agua del fondo concordaron con el patrón observado para el $\mathrm{Zn}$ en las branquias de mejillón, con concentraciones en ViB-1004 aproximadamente un orden de magnitud mayores que las concentraciones en otros puntos (Fig. 3). Se encontró una correlación significativa entre el $\mathrm{Zn}$ en las branquias de mejillón y el $\mathrm{Zn}$ disuelto en el agua del fondo ( $r=0.99, P<0.001, n=15)$, debido al mismo punto de muestreo (Tabla 2).

Se realizaron regresiones múltiples con todos los datos para analizar si la bioacumulación de metales podría ser modelada con una combinación de variables. Fue posible predecir bien el $\mathrm{Cu}$ en los tejidos blandos enteros y el $\mathrm{Cu}$ en las branquias de mejillón con el $\mathrm{Cu}$ disuelto en el agua del fondo y el $\mathrm{Cu}$ en el sedimento (Tabla 3). Lo mismo sucedió con el $\mathrm{Pb}$ en el agua del fondo y el $\mathrm{Pb}$ en los sedimentos. Por lo contrario, la modelación de $\mathrm{Pb}$ en las branquias de mejillón no mejoró al usar 2 variables, siendo el $\mathrm{Pb}$ disuelto en el agua del fondo el mejor predictor por sí solo. En el caso del Zn, las concentraciones en los tejidos blandos enteros presentaron la mejor predicción con las concentraciones de $\mathrm{Zn}$ en los sedimentos, y el Zn en las branquias de mejillón mostró la mejor predicción con las concentraciones de $\mathrm{Zn}$ disuelto en el agua del fondo (Tabla 2); no hubo una mejora significativa cundo se utilizó una variable adicional.

\section{Discusión}

Los mejillones pueden regular sus concentraciones internas de $\mathrm{Cu}$ dentro de ciertos límites (Amiard et al. 1987, Lorenzo et al. 2003, Lorenzo et al. 2005), pero a concentraciones de $\mathrm{Cu}$ muy altas en el medioambiente, esta capacidad de regulación se pierde. Debido a esto, es difícil encontrar correlaciones entre las concentraciones de $\mathrm{Cu}$ en los mejillones y las concentraciones de $\mathrm{Cu}$ en compartimentos 
integrate metal pollution at larger time scales than mussels do, and they show much more stable concentrations with time. Therefore, it seems that both gills and whole mussel soft tissues can respond to changes in dissolved $\mathrm{Pb}$ concentrations, so the use of gills does not represent an advantage over the use of whole mussel soft tissue for biomonitoring this metal.

As in the case of $\mathrm{Cu}$, bioavailability of $\mathrm{Zn}$ seems to be better reflected by gills than by whole mussel soft tissue. This is probably also due to the regulation of this essential metal at the whole organism level (Phillips and Yim 1981, Amiard et al. 1987). Zn concentrations ranged from 200 to $400 \mu \mathrm{g} \cdot \mathrm{g}^{-1} \mathrm{dw}$ in whole mussel soft tissue and did not seem to exceed that range even at highly polluted places such as harbor stations. On the contrary, Zn concentrations in the gills were lower and seemed to respond better to increases in the dissolved fraction (e.g., the ViB-1004 sampling point), whereas the concentration in whole mussel soft tissue did not.

Multiple regression analyses revealed that $\mathrm{Cu}$ and $\mathrm{Pb}$ bioaccumulation could be well predicted on the basis of metal concentrations in sediments and dissolved concentrations in bottom waters (Table 3). Despite particulate matter being an important source of metal to mussels via the digestive pathway, no significant correlations were found between metal concentrations in organisms and metal concentrations in the particulate form for any metal. The only metal showing significant correlations between mussels and TPM concentrations was $\mathrm{Cu}$ (Table 2), although this correlation was mainly due to a single sampling point, ViB-1004, showing much higher $\mathrm{Cu}$ in TPM than the other points. A study conducted by Gagnon et al. (2006) using the freshwater mussel Elliptio complanata showed a distinct bioaccumulation pattern for the gills and digestive glands of transplanted mussels. Their hypothesis, which ambientales como los sedimentos (Langston y Spence 1995, Hummel et al. 1997, Przytarska et al. 2010), excepto cuando se alcanzan niveles de contaminación de $\mathrm{Cu}$ muy altos (Beiras et al. 2003b), como se observó en el presente trabajo. Esto ha suscitado preguntas sobre la utilidad de los mejillones en el monitoreo de la contaminación de $\mathrm{Cu}$, y se ha propuesto el uso de otras especies filtradoras como las ostras, dado que las ostras aparentemente carecen de la capacidad para regular el $\mathrm{Cu}$ (Cooper et al. 1982, Lorenzo et al. 2003). Las branquias de mejillón parecen ser un complemento apropiado para el biomonitoreo del $\mathrm{Cu}$, ya que aparentemente responden más rápido a los cambios ambientales de $\mathrm{Cu}$ que el resto de los tejidos del mejillón (Sánchez-Marín et al. 2016). Esto se ejemplifica bien con los datos del punto de muestro ViB-1004, donde un incremento del $\mathrm{Cu}$ disuelto de un orden de magnitud comparado con otros puntos de muestreo se reflejó directamente en un incremento similar de un orden de magnitud en el $\mathrm{Cu}$ de las branquias, pero en el cuerpo entero este incremento fue mucho menor (Fig. 3). Además, en los sitios con nivel bajo o moderado de contaminación, con menos de $100 \mu \mathrm{g} \cdot \mathrm{g}^{-1} \mathrm{de}$ $\mathrm{Cu}$ en los sedimentos, las branquias de mejillón reflejaron mejor la variabilidad ambiental en las concentraciones de $\mathrm{Cu}$ que los tejidos blandos enteros. El $\mathrm{Cu}$ en las branquias de mejillón se correlacionó con el $\mathrm{Cu}$ en los sedimentos incluso cuando se excluyeron a los sitios portuarios del análisis (Tabla 2), mientras que los tejidos blandos enteros de mejillón en todos los sitios fuera del puerto mostraron concentraciones similares de $\mathrm{Cu}$.

En el caso del $\mathrm{Pb}$, tanto las branquias como los organismos enteros mostraron relaciones muy similares con los compartimentos ambientales abióticos, y sus concentraciones de $\mathrm{Pb}$ fueron muy similares, siguiendo de cerca la relación 1:1 aún en los sitios más contaminados (Fig. 2). Experimentos de laboratorio mostraron una muy rápida distribución del

Table 3. Significant multiple regressions of metal bioaccumulation in mussel tissues with metal concentrations in environmental compartments including all sampling points ${ }^{\mathrm{a}}$. Dissolved concentration in bottom water (Disbott), sediments (Sed). Tabla 3. Regresiones múltiples significativas de la bioacumulación de metales en los tejidos de mejillones con las concentraciones de metales en los compartimentos ambientales, con todos los puntos de muestreo incluidos ${ }^{\mathrm{a}}$. Concentración disuelta en agua del fondo (Disbott), sedimentos (Sed).

\begin{tabular}{lcc}
\hline Model & $r^{2}$ & $\begin{array}{c}P \text { value } \\
\left(\text { change in } r^{2}\right)^{\mathrm{b}}\end{array}$ \\
\hline $\mathrm{Cu}_{\text {Whole mussels }}=-0.08^{\text {n.s. }}( \pm 0.96)+5.29^{* * *}( \pm 0.17) \mathrm{Cu}_{\text {Disbott }}+0.083^{* * *}( \pm 0.007) \mathrm{Cu}_{\text {Sed }}$ & 0.992 & $P<0.001$ \\
$\mathrm{Cu}_{\text {Mussel gills }}=-18^{* *}( \pm 5)+31.4^{* * *}( \pm 0.83) \mathrm{Cu}_{\text {Disbott }}+0.15^{* * *}( \pm 0.03) \mathrm{Cu}_{\text {Sed }}$ & 0.993 & $P=0.001$ \\
$\mathrm{~Pb}_{\text {Whole mussels }}=-0.8^{\text {n.s. }}( \pm 0.8)+14.4^{* * *}( \pm 1.7) \mathrm{Pb}_{\text {Disbott }}+0.013^{*}( \pm 0.006) \mathrm{Pb}_{\text {Sed }}$ & 0.869 & $P=0.047$ \\
\hline
\end{tabular}

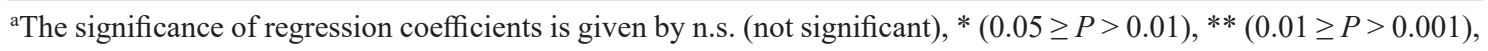
and $* * *(P \leq 0.001)$.

${ }^{\mathrm{b}}$ The $P$ value is given for the observed change in $r^{2}$ when changing the regression from simple to multiple. 
was similar to ours, pointed towards the use of mussel gills as bioindicators of dissolved metal bioavailability, and they also explored the use of digestive glands as bioindicators of particulate metal bioavailability. However, contrary to what was expected, Gagnon et al. (2006) found negative correlations between metal concentrations in gills and metal concentrations in the dissolved fraction, and no correlations between metals in the digestive gland and metals in the particulate form. This manifests the difficulty in finding consistent trends in these kinds of studies, given that many factors usually play a role in metal bioavailability and bioaccumulation, including biological factors such as mussel condition, stage of reproductive development, or ability to regulate body concentrations of some metals, and physicochemical factors such as variations in temperature, food availability, or changes in metal speciation. Bourgeault et al. (2011) showed that the amount of particulate metal assimilated by zebra mussels could be affected not only by the concentration of metal in the particulate form but also by metal speciation in particles and mussel filtration rate, which can vary from site to site; moreover, mussels can selectively ingest some particles and avoid others. These factors cause spatial variations in ingestion rates and assimilation efficiency (Bourgeault et al. 2011).

Temporal variability of metal concentrations in the water column-in both the dissolved and particulate phases-is expected to be very high and vary with tides, currents, and climatological events. Approaches using passive samplers such as diffusive gradients in thin films for dissolved metal and sediment traps for TPM allow obtaining metal concentrations representative of a longer period and would probably better reflect metal bioaccumulation. The analysis of labile fractions of metal in sediments, as opposed to total metal, allows estimations of bioavailable metal concentrations, and in some cases it yields better correlations with metal concentrations in bivalves (Yap et al. 2002, Amiard et al. 2007). However, issues associated with the regulation of essential metal concentrations in the body still mask pollution levels when using bivalve biomonitors.

In summary, the present results indicate that the use of mussel gills in biomonitoring metal pollution is promising because these tissues can record changes in the concentrations of the dissolved forms of bioavailable metals in the environment, especially at high levels of essential metals such as $\mathrm{Cu}$ and $\mathrm{Zn}$, which are regulated at the whole body level. To further confirm this assertion, it would be desirable to extend this study to include more sampling points, including bodies of water with different levels of metal pollution. This can be done by including the analysis of mussel gills and of dissolved and particulate metals in investigative monitoring, preferably employing passive sampling devices, in addition to other most commonly sampled environmental matrices.
$\mathrm{Pb}$ en los tejidos de mejillón. En un estudio sobre la cinética de captación del $\mathrm{Pb}$ disuelto, las concentraciones de $\mathrm{Pb}$ en las branquias y en el resto de los tejidos fueron similares en todos los tiempos de muestreo (de $1 \mathrm{a} 24$ h) (SánchezMarín et al. 2011). La alta concentración de Pb en ViB-1004, tanto en los mejillones como en la fase disuelta, revela que los mejillones reflejan un incremento real, y probablemente reciente, en la concentración de $\mathrm{Pb}$ biodisponible, aunque esto no se refleje en los sedimentos. Los sedimentos integran la contaminación a escalas de tiempo mayores de lo que lo hacen los mejillones, y muestran concentraciones mucho más estables con el tiempo. Por lo tanto, parece que tanto las branquias como los tejidos blandos enteros de mejillón son capaces de responder a los cambios en las concentraciones $\mathrm{de} \mathrm{Pb}$ disuelto, y el uso de las branquias no representa una ventaja sobre el uso del tejido blando entero para biomonitorear este metal.

En cuanto al $\mathrm{Cu}$, la biodisponibilidad del $\mathrm{Zn}$ parece reflejarse mejor en las branquias que en los tejidos blandos enteros de mejillón. Esto probablemente se debe a la regulación de este metal esencial a nivel del organismo entero (Phillips y Yim 1981, Amiard et al. 1987). Las concentraciones de Zn variaron de $200 \mathrm{a} 400 \mu \mathrm{g} \cdot \mathrm{g}^{-1} \mathrm{ps}$ en los tejidos blandos enteros de mejillón, y aparentemente no excedieron este intervalo ni en los sitios altamente contaminados, como las estaciones portuarias. Por lo contrario, las concentraciones de $\mathrm{Zn}$ en las branquias de mejillón fueron más bajas y parecieron responder mejor a los incrementos en la fracción disuelta (e.g., el punto de muestreo ViB-1004), pero la concentración en los tejidos blandos enteros no.

Los análisis de regresión múltiple revelaron que la bioacumulación de $\mathrm{Cu}$ y $\mathrm{Pb}$ podía predecirse bien con base en las concentraciones de metales en los sedimentos y las concentraciones disueltas en el agua del fondo (Tabla 3). A pesar de que la materia particulada es una fuente importante de metales para los mejillones vía la ruta digestiva, no se encontraron correlaciones significativas entre las concentraciones de metales en los organismos y las concentraciones de metales en la forma particulada para ningún metal. El único metal que mostró correlaciones significativas entre mejillones y el MPT fue el Cu (Tabla 2), aunque esta correlación se debió mayormente a un único punto de muestreo, ViB-1004, donde la concentración de $\mathrm{Cu}$ fue mucho mayor en MPT que en los otros puntos. Un estudio realizado por Gagnon et al. (2006) con el mejillón de agua dulce Elliptio complanata mostró un patrón de bioacumulación diferente para las branquias y las glándulas digestivas de mejillones trasplantados. Su hipótesis, similar a la nuestra, apuntaba hacia el uso de las branquias de mejillón como bioindicadores de la biodisponibilidad de metal disuelto, y también postularon el uso de las glándulas digestivas como bioindicadores de la biodisponibilidad del metal particulado. Sin embargo, contrariamente a lo esperado, Gagnon et al. (2006) encontraron correlaciones negativas entre las concentraciones de metal en las branquias y las 


\section{ACKNOWLedgments}

This study was supported by the Spanish government (project no. REN2003-00958) and the Galician government (project no. PGIDIT10MDS700006PR).We thank I Durán and JI Lorenzo for their participation in previous stages of this work, and F Schultze and the technical staff at the Chemical Pollution Laboratory of the Centro Oceanográfico de Vigo (Instituto Español de Oceanografía) for their assistance during sampling, sample preparation, and chemical analyses.

\section{REFERENCES}

Amiard JC, Amiard-Triquet C, Berthet B, Metayer C. 1987. Comparative study of the patterns of bioaccumulation of essential $(\mathrm{Cu}, \mathrm{Zn})$ and non-essential $(\mathrm{Cd}, \mathrm{Pb})$ trace metals in various estuarine and coastal organisms. J. Exp. Mar. Biol. Ecol. 106(1): 73-89. https://doi.org/10.1016/0022-0981(87)90148-1

Amiard JC, Geffard A, Amiard-Triquet C, Crouzet C. 2007. Relationship between the lability of sediment-bound metals $(\mathrm{Cd}, \mathrm{Cu}, \mathrm{Zn})$ and their bioaccumulation in benthic invertebrates. Estuar. Coast. Shelf. Sci. 72(3): 511-521. https://doi.org/10.1016/j.ecss.2006.11.017

Baumard P, Budzinski H, Garrigues P, Dizer H, Hansen PD. 1999. Polycyclic aromatic hydrocarbons in recent sediments and mussels (Mytilus edulis) from the Western Baltic Sea: occurrence, bioavailability and seasonal variations. Mar. Env. Res. 47(1): 17-47. https://doi.org/10.1016/s0141-1136(98)00105-6

Beiras R, Bellas J, Fernández N, Lorenzo JI, Cobelo-García A. 2003a. Assessment of coastal marine pollution in Galicia (NW Iberian Peninsula); metal concentrations in seawater, sediments and mussels (Mytilus galloprovincialis) versus embryo-larval bioassays using Paracentrotus lividus and Ciona intestinalis. Mar. Environ. Res. 56(4): 531-553.

https://doi.org/10.1016/s0141-1136(03)00042-4

Beiras R, Durán I, Parra S, Urrutia MB, Besada V, Bellas J, Viñas L, Sánchez-Marín P, González-Quijano A, Franco MA, Nieto Ó, González JJ. 2012. Linking chemical contamination to biological effects in coastal pollution monitoring. Ecotoxicology 21(1): 9-17.

https://doi.org/10.1007/s10646-011-0757-3

Beiras R, Fernández N, Bellas J, Besada V, González-Quijano A, Nunes T. 2003b. Integrative assessment of marine pollution in Galician estuaries using sediment chemistry, mussel bioaccumulation, and embryo-larval toxicity bioassays. Chemosphere 52(7): 1209-1224. https://doi.org/10.1016/s0045-6535(03)00364-3

Besada V, Andrade JM, Schultze F, Fumega J, Cambeiro B, González JJ. 2008. Statistical comparison of trace metal concentrations in wild mussels (Mytilus galloprovincialis) in selected sites of Galicia and Gulf of Biscay (Spain). Journal of Marine Systems 72(1-4): 320-331. https://doi.org/10.1016/j.jmarsys.2007.03.012

Bourgeault A, Gourlay-Francé C, Priadi C, Ayrault S, TusseauVuillemin MH. 2011. Bioavailability of particulate metal to zebra mussels: Biodynamic modelling shows that assimilation efficiencies are site-specific. Environ. Pollut. 159(12): 33813389.

https://doi.org/10.1016/j.envpol.2011.08.034 concentraciones de metal en la fracción disuelta, y ninguna correlación entre los metales en la glándula digestiva y los metales en la forma particulada. Esto refleja la dificultad de encontrar patrones consistentes en estos tipos de estudios, dado que muchos factores suelen jugar un papel en la biodisponibilidad y la bioacumulación de metales, incluso factores biológicos como la condición del mejillón, su estado de desarrollo reproductivo o su capacidad de regular las concentraciones corporales de algunos metales, y factores fisicoquímicos como las variaciones de temperatura, la disponibilidad de alimento o los cambios en la especiación de los metales. Bourgeault et al. (2011) mostró que la cantidad de metal particulado asimilada por los mejillones podía verse afectada no solo por la concentración del metal en la forma particulada, sino también por la especiación del metal en las partículas y la tasa de filtración de los mejillones, la cual varía de sitio a sitio; además, los mejillones pueden ingerir selectivamente algunas partículas y evitar otras. Estos factores generan variaciones espaciales en las tasas de ingestión y en la eficiencia de asimilación (Bourgeault et al. 2011).

Se espera que la variabilidad temporal en las concentraciones de metales en la columna de agua, tanto en la fase disuelta como en la fase particulada, sea muy alta y varíe con las mareas, las corrientes y los eventos climatológicos. Los enfoques que utilizan muestreadores pasivos, tales como los gradientes difusivos en películas delgadas para metales disueltos y las trampas de sedimentos para el MPT, permiten obtener concentraciones de metales representativas de un periodo más largo y probablemente reflejarían mejor la bioacumulación de metales. El análisis de las fracciones lábiles de metales en los sedimentos, contrario a metales totales, permite estimar las concentraciones de metal biodisponible, y en algunos casos genera mejores correlaciones con las concentraciones de metales en los bivalvos (Yap et al. 2002, Amiard et al. 2007). Sin embargo, los asuntos relacionados con la regulación de las concentraciones de metales esenciales en el cuerpo continúan enmascarando los niveles de contaminación cuando los bivalvos son utilizados como biomonitores.

En resumen, los presentes resultados indican que el uso de las branquias de mejillón en el biomonitoreo de la contaminación por metales es prometedor porque identifican cambios en las concentraciones de las formas disueltas de los metales biodisponibles en el ambiente, especialmente a niveles altos de metales esenciales como el $\mathrm{Cu}$ y el $\mathrm{Zn}$, que son regulados en el cuerpo entero. Para confirmar esta aserción, sería deseable extender este estudio de forma que se incluyan más puntos de muestreo, como cuerpos de agua con diferentes niveles de contaminación. Esto puede realizarse si se incluye el análisis de las branquias de mejillón y de los metales disueltos y particulados en los monitoreos investigativos, preferentemente con el uso de muestreadores pasivos, además del análisis de otras matrices ambientales comúnmente muestreadas. 
Campbell PGC. 1995. Interactions between trace metals and aquatic organisms: A critique of the free-ion activity model. In: Tessier A,Turner DR (eds.), Metal Speciation and Bioavailability in Aquatic Systems. Wiley, New York, pp. 45-102.

Cooper RJ, Langlois D, Olley J. 1982. Heavy metals in Tasmanian shellfish. I. Monitoring heavy metal contamination in the Derwent estuary: Use of oysters and mussels. J. Appl. Toxicol. 2(2): 99-109. https://doi.org/10.1002/jat.2550020208

Di Toro DM, Allen HE, Bergman HL, Meyer JS, Paquin PR, Santore RC. 2001. Biotic ligand model of the acute toxicity of metals. 1. Technical basis. Environ. Toxicol. Chem. 20(10): 2383-2396.

Gagnon C, Gagné F, Turcotte P, Saulnier I, Blaise C, Salazar MH, Salazar SM. 2006. Exposure of caged mussels to metals in a primary-treated municipal wastewater plume. Chemosphere 62(6): 998-1010. https://doi.org/10.1016/j.chemosphere.2005.06.055

Giarratano E, Duarte CA, Amin OA. 2010. Biomarkers and heavy metal bioaccumulation in mussels transplanted to coastal waters of the Beagle Channel. Ecotox. Environ. Safe. 73(3): $270-279$. https://doi.org/10.1016/j.ecoenv.2009.10.009

Griscom SB, Fisher NS, Luoma SN. 2002. Kinetic modeling of Ag, $\mathrm{Cd}$ and $\mathrm{Co}$ bioaccumulation in the clam Macoma balthica: quantifying dietary and dissolved sources. Mar. Ecol. Prog. Ser. 240: $127-141$. https://doi.org/10.3354/meps240127

Gundacker C. 1999. Tissue-specific heavy metal (Cd, Pb, Cu, Zn) deposition in a natural population of the zebra mussel Dreissena polymorpha Pallas. Chemosphere 38(14): 3339-3356. https://doi.org/10.1016/s0045-6535(98)00567-0

Hummel H, Modderman R, Amiard-Triquet C, Rainglet F, VanDuijn Y, Herssevoort M, De Jong J, Bogaards R, Bachelet G, Desprez M, et al. 1997. A comparative study on the relation between copper and condition in marine bivalves and the relation with copper in the sediment. Aquat. Toxicol. 38(1-3): $165-181$. https://doi.org/10.1016/s0166-445x(96)00832-6

Kimbrough KL, Johnson WE, Lauenstein GG, Christensen JD, Apeti DA. 2008. An assessment of two decades of contaminant monitoring in the nation's coastal zone, Silver Spring, MD. NOAA Tech. Mem. NOS NCCOS 74, 105 pp.

Langston WJ, Spence SK. 1995. Biological factors involved in metal concentrations observed in aquatic organisms. In: Tessier A,Turner DR (eds.), Metal Speciation and Bioavailability in Aquatic Systems. Wiley, New York, pp. 407-478.

Lorenzo JI, Beiras R, Aierbe E, Mubiana VK, Blust R. 2003. Indications of regulation on $\mathrm{Cu}$ accumulation in the blue mussel Mytilus edulis. Proceedings, 4th International Conference in Molluscan Shellfish Safety: 533-544.

Lorenzo JI, Beiras R, Mubiana VK, Blust R. 2005. Copper uptake by Mytilus edulis in the presence of humic acids. Environ. Toxicol. Chem. 24(4): 973-980. https://doi.org/10.1897/04-216r.1

Luoma SN, Rainbow PS. 2005. Why is metal bioaccumulation so variable? Biodynamics as a unifying concept. Environ. Sci. Technol. 39(7): 1921-1931. https://doi.org/10.1021/es048947e

Phillips DJH, Yim WWS. 1981. A comparative evaluation of oysters, mussels and sediments as indicators of trace metals in

\section{Agradecimientos}

El presente estudio recibió apoyo por parte del gobierno español (proyecto no. REN2003-00958) y del gobierno de Galicia (proyecto no. PGIDIT10MDS700006PR). Agradecemos a I Durán y a JI Lorenzo su participación en las etapas previas de este trabajo, y a F Schultze y al equipo técnico del Laboratorio de Contaminación Química del Centro Oceanográfico de Vigo (Instituto Español de Oceanografía) su asistencia durante el muestreo, la preparación de las muestras y los análisis químicos.

Traducido al español por Monica Bricelj.

Hong Kong waters. Mar. Ecol. Prog. Ser. 6: 285-293. https://doi.org/10.3354/meps006285

Przytarska JE, Sokołowski A, Wołowicz M, Hummel H, Jansen J. 2010. Comparison of trace metal bioavailabilities in European coastal waters using mussels from Mytilus edulis complex as biomonitors. Environmental Monitoring and Assessment 166(1-4): 461-476. https://doi.org/10.1007/s10661-009-1015-5

[QUASIMEME] Quality Assurance of Information in Marine Environmental Monitoring in Europe. 2005. QUASIMEME laboratory performance studies. Round 40. Exercise 648,649,650 (sediments) and 651,652 and 654 (biota). QUASIMEME Laboratory Performance Studies, Wageningen University and Research, The Netherlands.

Sánchez-Marín P, Aierbe E, Lorenzo JI, Mubiana VK, Beiras R, Blust R. 2016. Dynamic modeling of copper bioaccumulation by Mytilus edulis in the presence of humic acid aggregates. Aquat. Toxicol. 178: 165-170. https://doi.org/10.1016/j.aquatox.2016.07.021

Sánchez-Marín P, Bellas J, Mubiana VK, Lorenzo JI, Blust R, Beiras R. 2011. Pb uptake by the marine mussel Mytilus sp. Interactions with dissolved organic matter. Aquat. Toxicol. 102(1-2): 48-57. https://doi.org/10.1016/j.aquatox.2010.12.012

Sericano JL. 2000. The mussel watch approach and its applicability to global chemical contamination monitoring programmes. Int. J. Environ. Pollut. 13(1/2/3/4/5/6): 340-350. https://doi.org/10.1504/ijep.2000.002323

Sokal RR, Rohlf FJ. 1995. Biometry: The Principles and Practice of Statistics in Biological Research. W.H. Freeman and Company, USA.

Solaun O, Rodríguez JG, Borja A, Larreta J, Valencia V. 2015. Relationships between polychlorinated biphenyls in molluscs, hydrological characteristics and human pressures, within Basque estuaries (northern Spain). Chemosphere 118: 130-135. https://doi.org/10.1016/j.chemosphere.2014.07.053

Yap CK, Ismail A, Tan SG, Omar H. 2002. Correlations between speciation of $\mathrm{Cd}, \mathrm{Cu}, \mathrm{Pb}$ and $\mathrm{Zn}$ in sediment and their concentrations in total soft tissue of green-lipped mussel Perna viridis from the west coast of Peninsular Malaysia. Environ. Int. 28(1-2): 117-126. https://doi.org/10.1016/s0160-4120(02)00015-6

Received February 2018, accepted October 2018. 